\title{
The distribution of antibodies to streptokinase
}

\author{
Mary Lynch, Brian L Pentecost, William A Littler, Robert A Stockley
}

\begin{abstract}
Summary
To determine the distribution of antibodies to streptokinase that might be anticipated in patients requiring treatment with streptokinase, specific antistreptokinase antibody titres were determined in a group of subjects from the general population and in a group of patients presenting with acute myocardial infarction. Enzyme-linked immunosorbent assays were developed to measure specific anti-streptokinase IgG and subclass $I_{g G_{1}}$ in 95 subjects from the general population and in 160 patients presenting with acute myocardial infarction. Low titres of $\mathrm{IgG}_{1}$ were found in both the general population (median $=5$; range: $0-490$ ) and in the myocardial infarction group (median $=7$; range: 0-2000). A minority of subjects in both groups had high titres. The findings suggest that low titres of antibody are widespread in the population. The minority of subjects in both groups who had high titres may explain the infrequent type III immune reactions encountered with streptokinase.
\end{abstract}

Keywords: streptokinase, antibodies

Streptokinase, a protein produced by betahaemolytic streptococci, is the most widely used and least expensive thrombolytic agent. However, a disadvantage to its use is its antigenicity due to the widespread presence of antibodies in the population, presumed secondary to previous streptococcal exposure or infection. To induce a thrombolytic state, streptokinase must neutralise these antibodies as well as the endogenous inhibitors of fibrinolysis. ${ }^{1,2}$ The distribution of these antibodies has been previously evaluated in hospitalised patients. ${ }^{1,3}$ However, this may not be representative of the range of antibody titres found in the general population which has not been determined. Such an evaluation would indicate the range of titres that might be expected in any patient requiring treatment with streptokinase. It is now accepted that the administration of streptokinase in the presence of a significant titre of specific antibody could result in an immune reaction such as serum sickness ${ }^{4}$ or impair the efficacy of the thrombolytic state induced.,

The aims of this study were to document the range of streptokinase antibodies in the general population and to compare the distribution found to that of patients presenting with acute myocardial infarction.

\section{Subjects}

Ninety-five subjects, including at least six men and six women from each decade from 20 to 80 years, were recruited from the general population. No subject had a recent history suggestive of a streptococcal infection or had been previously treated with streptokinase. A total of 160 patients with acute myocardial infarction presenting to a teaching hospital were recruited. The diagnosis of myocardial infarction was based on a history of chest pain, definite electrocardiographic evidence (1 $\mathrm{mm}$ ST elevation in two or more limb leads and $2 \mathrm{~mm}$ ST elevation in two or more chest leads) and confirmed by a subsequent rise in serum aspartate transaminase to more than twice the upper normal limit.

\section{Methods}

All subjects consented to provide a $10 \mathrm{ml}$ sample of venous blood. The myocardial infarction patients had blood taken on admission, prior to any treatment. Enzyme-linked immunosorbent assays for specific antistreptokinase $\mathrm{IgG}$ and $\mathrm{IgG}_{1}$ were developed and antibody titres were assayed for IgG and subclass $\mathrm{IgG}_{1}$ as previously described. ${ }^{6}$ Briefly, the wells of microtitre plates were coated with $200 \mathrm{ml}$ of $300 \mathrm{IU}$ of streptokinase (Kabivitrum Pharmaceuticals) in $0.05 \mathrm{M}$ carbonate/ bicarbonate buffer ( $\mathrm{pH} 9.5$ ) and incubated for $16 \mathrm{~h}$ at $4^{\circ} \mathrm{C}$. Following three washes with phosphate-buffered saline containing $0.01 \%$ Tween, several dilutions of patient serum were added to the wells in the same buffer and incubated at room temperature for two hours. Following three further washes, horseradish peroxidase conjugated to sheep anti-human immunoglobulin (Immunodiagnostic Research Laboratory, Univerity of Birmingham, UK) was added and the plate incubated at room temperature for a further two hours. Following a further series of washes, hydrogen peroxidase/o-phenylenediamine (Sigma, UK) in phosphate citrate buffer ( $\mathrm{pH} 5$ ) was added. When the colour change of the known standard included on every plate reached a predetermined value, the reaction was stopped by the addition of $0.5 \mathrm{M}$ citric acid. The optical density was read at $490 \mathrm{~nm}$. Results were expressed with reference to a fixed dilution on the standard curve. The standard serum was obtained from a patient who had been treated with streptokinase 10 days previously. Reproducibility of the $I g G$ and $I_{g G}$ assays was determined at the upper and lower ranges. At a mean IgG titre of 4200 , the within-batch 
coefficient of variation (CV) was $6.9 \%$ and between-batch CV was $12.9 \%$, and at a mean titre of 19 , the within-batch $C V$ was $14.7 \%$ and between-batch CV was $29 \%$. For $\mathrm{IgG}_{1}$, the within-batch $\mathrm{CV}$ for a mean titre of 1750 was $7.7 \%$ and between-batch CV was $14.2 \%$, and at a mean titre of 12 the within-batch $\mathrm{CV}$ was $12.7 \%$ and between-batch CV was $31.8 \%$.

The antibody titres from all groups are expressed as median and range. The figures demonstrate the distribution of individual titres. The statistical significance of differences between groups was determined by Chi-square analysis. Ethical permission was granted by the local ethics committee.

\section{Results}

The general population group of subjects included 44 males and 51 females. Fifty-eight $(61 \%)$ had detectable IgG antibodies to streptokinase. These titres varied from 0 to 490 with a median of 7 (figure). For the 44 male subjects, $28(63 \%)$ had detectable titres (median = 8.5; range: $0-260)$. A similar pattern was seen in the 51 female subjects assessed, 30 subjects (59\%) had detectable IgG antibodies to streptokinase (median $=5$; range: $0-490$ ). When this group was subdivided on the basis of age, there was no difference in the median titres for each decade (table). While more female subjects had higher titres than male subjects, this did not reach statistical significance.

The results of the $\operatorname{IgG}_{1}$ titres were similar. Fifty one of the subjects $(53.6 \%)$ had detectable $\mathrm{IgG}_{1}$ titres. The titres varied from 0 to 250 (median $=2$ ). For the male subjects, the median IgG $_{1}$ titre was 3 (range: $0-250$ ). This was similar to the female group (median $=0$; range: 0-200). Again there was no relationship between titre and age.

The group of patients presenting with myocardial infarction included 117 males and 43 females (aged 36-85 years). Four patients

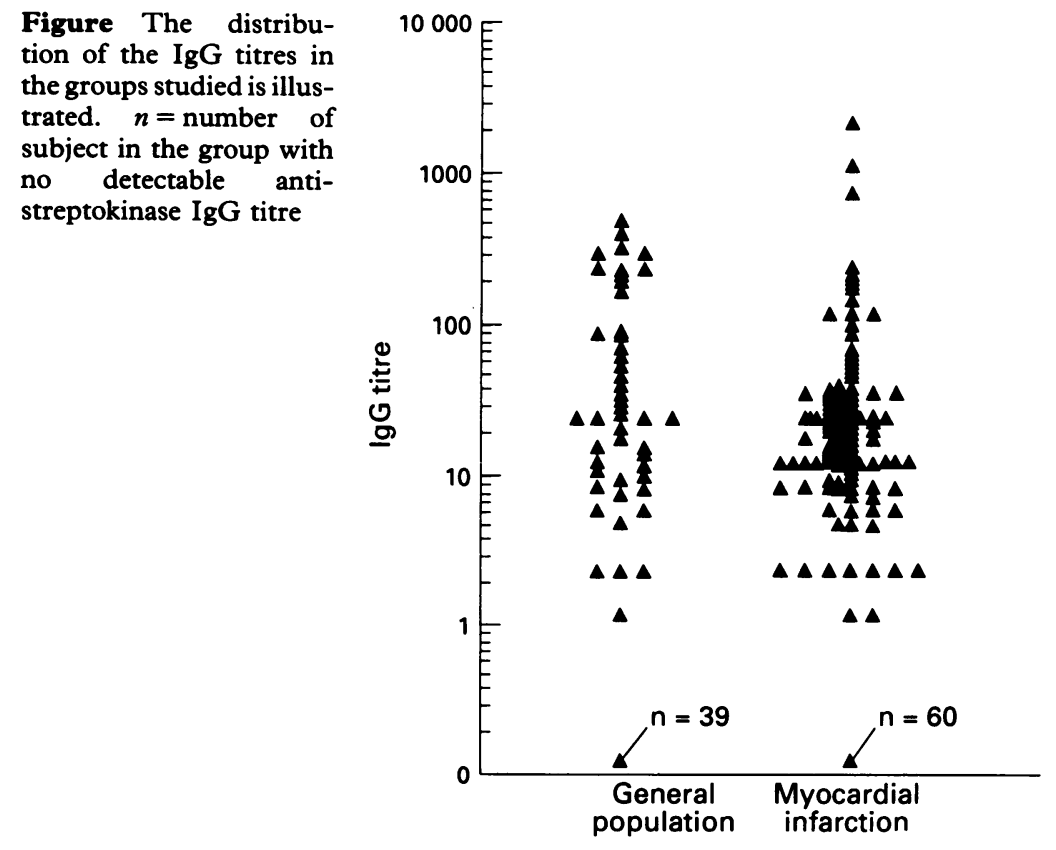

Table Antistreptokinase IgG titres for each decade among the male and female subjects recruited from the general population

\begin{tabular}{lrc}
\hline Decade & $n$ & Median titre (range) \\
\hline Male subjects & & \\
$20-29$ & 7 & $5(0-39)$ \\
$30-39$ & 7 & $13(0-32)$ \\
$40-49$ & 8 & $10(0-68)$ \\
$50-59$ & 7 & $13(0-48)$ \\
$60-69$ & 9 & $20(0-260)$ \\
$70-79$ & 6 & $0(0-9)$ \\
Female subjects & & \\
$20-29$ & 6 & $7(0-58)$ \\
$30-39$ & 7 & $18(0-175)$ \\
$40-49$ & 14 & $11(0-420)$ \\
$50-59$ & 11 & $0(0-200)$ \\
$60-69$ & 7 & $1(0-490)$ \\
$70-79$ & 6 & $5(0-75)$ \\
\hline
\end{tabular}

had prior treatment with streptokinase (between three days and six months previously). Detectable IgG titres were found in 100 patients $(62.5 \%)$, the median titre was 7 (range: 0-2000) (figure). The patients with the markedly high titres $(>200)$ had been previously treated with streptokinase (they received tissue plasminogen activator on this presentation). If this group of patients who previously received streptokinase $(n=4)$ is omitted, the range of titres is similar to that of the general population group (median $=5.5$; range: $0-200)$. The $\operatorname{IgG}_{1}$ titres showed a similar distribution (median $=2.5$; range: 0-550).

There was no significant difference between the two groups. We have previously studied the immunoglobulin response to a bolus dose of streptokinase $\left(1.6 \times 10^{6} \mathrm{IU}\right)$ in patients with acute myocardial infarction and found that titres remain significantly elevated over baseline levels at one year post therapy at which time the median titre was $85 .^{6}$ In this study, a small number of patients in both groups, who had not previously received treatment with streptokinase, had titres greater than $85(11.5 \%$ in the general population group $[n=11]$ and $6.2 \%$ in the myocardial infarction group $[n=10])$. Repeat treatment with streptokinase is not advised within the initial year of treatment because of the theoretical increased likelihood of immune reactions occurring. ${ }^{7}$

\section{Discussion}

Information on the distribution of antistreptokinase antibodies was obtained in a group of subjects representative of the general population, which would reflect the distribution of antibodies likely to be encountered in subjects requiring treatment with streptokinase. Both this group and the myocardial infarction group had a wide range of titres although the median values were low. The percentage of subjects with detectable antibody titres and the distribution of these titres were similar in both groups. While the titres were biased toward the lower values, a small proportion of patients in both groups had titres greater 


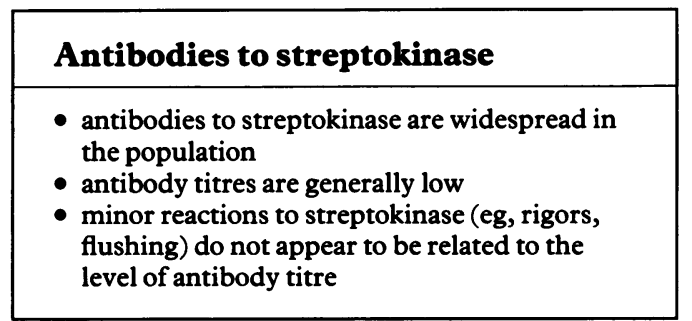

Box 1

than would be expected, on average, in a subject treated one year previously with streptokinase. It is advised by the pharmaceutical companies that market streptokinase that it should not be repeated within a year of initial therapy, because of the risk of allergic reactions thought to be associated with high antibody titres. ${ }^{7}$ The efficacy of the thrombolytic state induced in the presence of high titres would also be in doubt. ${ }^{2,6}$ This would suggest that titres greater than those occurring at one year should be regarded as potentially hazardous. The finding of high circulating anti-streptokinase IgG titres in both groups would indicate that a proportion of the general population who had no previous streptokinase treatment could be as much at risk of an immune reaction to

1 James DCO. Anti-streptokinase levels in various hospita patient groups. Postgrad Med f 1973; 49 (suppl): 26-9.

2 Spottl F, Kaiser R. Rapid detection and quantitation of precipitating streptokinase-antibodies. Thromb Diath precipitating streptokinase-
Haemorrh 1974; 32: 608-16.

3 Flute PT. The significance of streptokinase antibody. Postgrd Med $\mathcal{f} 1970 ; 46$ (suppl): 24-5.

4 grd Med f 1970; 46 (suppl): 24-5. McGrath KG, Patterson R. Immunology of streptokinase
human subjects. Clin Exp Immunol 1985; 62: 536-48.

5 Lynch M, Pentecost BL, Littler WA, Stockley RA. The significance of anti-streptokinase antibodies. Clin Exp Immunol 1994; 96: 427-31.

6 Lynch M, Littler WA, Pentecost BL, Stockley RA.The immunoglobulin response to intravenous streptokinase in acute myocardial infarction. Br Heart $\mathcal{F}$ 1991; 66: 139-42.

\section{Learning points}

- a small percentage of subjects have high titres $(10 \%)$ of streptokinase antibodies

- no difference was found in the levels of antibody titre among different age groups or between sexes

- subjects with high titres may account for those who develop more serious reactions to streptokinase

Box 2

streptokinase as subjects who had received it in the last year.

The specific anti-streptokinase antibodies found in all groups studied, $\mathrm{IgG}_{1}$, are typical of the immunoglobulin response to a protein antigen. ${ }^{8}$ Our findings suggest that low antibody titres are widespread in the population but a minority of subjects have comparatively elevated titres. While antibody titres have not been demonstrated to relate to the minor acute reactions encountered with streptokinase therapy, ${ }^{9}$ this group with high titres may potentially account for the small incidence of more serious delayed reactions such as serum sickness seen with streptokinase.

7 APBI Data Sheet Compendium 1994-1995. Datapharm Publications, pp 680-2. (Data sheet 'Kabikinase') Pp 584-586, 'Dp 680 2. (Data

8 ptevens $R$, Dichek $D$, Keld $B$, Heiner D. IgG1 is the predominant subclass of in vivo and in vitro produced predominant subclass of in vivo and in vitro produced anti-tetanus toxoid antibodies and also serves as the membrane IgG molecule for delivering inhibitory signals to anti-toxoid

9 Lynch M, Pentecost BL, Littler WA, Stockley RA. Why do patients develop reactions to streptokinase? Clin Exp Immunol 1993; 94: 279-85. 